\title{
A 2-stage hierarchical interrupted time-series analysis to quantify the long-term effect of subclinical Bacterial Kidney Disease on performance of farmed Atlantic Salmon (Salmo salar L.)
}

\author{
A.S. Boerlage ${ }^{a c}$, H. Stryhn ${ }^{a}$, B. Armstrong ${ }^{b}$, K.L. Hammella
}

a: Department of Health Management and Centre for Veterinary Epidemiologic Research (CVER), Atlantic Veterinary College, University of Prince Edward Island, Charlottetown, Canada.

b: Department of Social and Environmental Health Research, London School of Hygiene \& Tropical Medicine, London, UK.

c: Current address: Epidemiological Research Unit of Scotland's Rural College, Inverness, UK.

corresponding author: annette.boerlage@sruc.ac.uk

Preventive Veterinary Medicine, Volume 172, 15 November 2019, 104776 (Version accepted for publication.)

\begin{abstract}
Bacterial Kidney Disease (BKD) is an economically significant disease in salmonid aquaculture and commonly requires antibiotic treatments to reduce its impact. Once a pen of fish is diagnosed with BKD, fish are considered chronically infected, potentially until harvest. Although there appears to be little or no evidence to support it, it is often assumed that subclinical infections affect productivity over the long term. We used a 2-stage hierarchical interrupted time series (ITS) analysis in an attempt to quantify the effect of subclinical BKD on mortality, growth, and food conversion ratio (FCR) of Atlantic salmon cultured in marine farms in Atlantic Canada. For all three outcomes, BKD had for some site cycles a positive effect, and for others a negative effect. Overall, the effect of BKD on mortality and growth could not be detected (effect -0.08 ((95\% ci: $-0.51,0.35)$ and $0.00(-0.02,0.02))$, while a very small effect showing an increase in FCR was detected $(0.07$ ($0.01,0.15)$ ). We hypothesized that minimal interference with fish performance may be compatible with the ecology of Renibacterium salmoninarum, the causative agent of BKD. For this organism, vertical transmission is a primary mode of propagation in low-density host populations as found in the wild. Since farms are always adapting and optimizing their farm management of BKD, these constant adjustments may also have negated our ability to detect the effect of many factors contributing to BKD productivity impacts. Hierarchical ITS analysis is considered an appropriate methodology to investigate the complex relationships with productivity measures over time under farming conditions. In the highly innovative salmon aquaculture industry, health records generating data available for time-series analysis is expected to become more accurate and abundant in the future, providing more opportunities for time-series regression studies.
\end{abstract}

Keywords : Time-series regression (TSR), subclinical, Bacterial Kidney Disease (BKD), mortality, Food Conversion Ratio (FCR), growth, Atlantic salmon 


\section{Introduction}

Bacterial Kidney Disease (BKD) affects all life stages of wild and cultured salmonids around the world (Toranzo et al., 2005), and can be a frequent reason for antibiotic use in salmonid aquaculture. The causative agent for BKD is Renibacterium salmoninarum, a bacteria that is transmitted both vertically (Evelyn et al., 1984) and horizontally (Balfry et al., 1996; Evenden et al., 1993). An infection with $R$. salmoninarum is considered chronic and may persist until death (Banner et al., 1986). Once infected, fish can present with clinical or subclinical disease (Murray et al., 2011), and can change between these 2 states through time. In marine reared salmon, a pen with clinical BKD refers to a pen with elevated mortality (e.g. $2 \%$ in a running 4 week period (Boerlage et al., 2017)), in which some, but not all, fish have clinical signs including lesions typical for BKD, such as lethargy, skin darkening, ascites, pale gills (anaemia), exophthalmia, anal vent haemorrhage, and greyish-white granulomatous lesions in the viscera or brain (Wiens, 2011). Provided an infected fish survives, clinical BKD may occur over several weeks, after which fish become subclinically infected; mortality diminishes to levels that are low and undistinguishable from background mortality (Lovely et al., 1994), and few clinical signs are observed. However, occasional mortalities may still demonstrate typical BKD lesions without a noticeable increase in daily mortality rates. Onset of a clinically-infected period depends on interactions between pathogen, environment and management factors, such as stocking season and good husbandry practices (Boerlage et al., 2018). While in theory subclinical BKD precedes clinical BKD (Murray et al., 2011), subclinical BKD states may not be detected in areas lacking active surveillance for BKD or infections with $R$. salmoninarum. In some cases, subclinically infected pens never reach mortality levels sufficiently high to classify them as clinical during the entire production cycle.

It is often assumed that subclinical infection with $R$. salmoninarum must at some level affect performance measures such as mortality, growth rates, and Food Conversion Ratio (FCR) (Burnley et al., 2010; Vigneulle and Bruno, 2015), but effects of a chronic presence of BKD on productivity, especially during subclinical presentation, are not well described. One of the main reasons for the absence of this information is the multitude of interacting factors occurring in natural infections and the lack of reliable estimates of both growth and corresponding infection incidence at either the individual or population level. There have been a few experimental studies with a relatively short duration. For instance, BKD related mortalities in chinook salmon (Oncorhynchus tshawytscha) labeled "low BKD progeny" by enzyme-linked immunosorbent assay (ELISA) and fluorescent antibody technique (FAT) in a previous brood stock segregation study (Pascho et al., 1991) were undetected (Elliott et al., 1995) after 11 weeks of salt-water rearing. In another study, a two-month infection challenge, mortality of fish infected with $R$. salmoninarum, detected by ELISA, was higher than for control fish (Mesa et al., 2000). Short experimental studies are prone to very slight effects at fish level being attributed to normal variation, whereas true effects, even if slight, can have large cumulative impacts in aquaculture at the farm level, during the long (ca. 2 years) production cycle. Controlled trials that last a production cycle are impractical, because of the large sample size that would be needed to control for seasonal and management effects and the inability to detect changing circumstances with natural infections. Another approach would be to do a retrospective observational study using the large amount of historical records available in the farm management systems of aquaculture farms. In our case, almost $90 \%$ of the sites were associated with some level of BKD (Boerlage et al., 2017), and there were strong seasonal and year effects on BKD (Boerlage et al., 2018), so that a case-control study would not provide the required control sites. In addition, the effect of BKD might not be absolute, but rather a change in trend, e.g. reduced growth rate.

One study design that is increasingly being used to evaluate long-term effect of interventions at population level is the interrupted time series (ITS) (Bernal et al., 2017). Examples of studies that used ITS are the effect of opioid overdose education on opioid overdose rates (Walley et al., 2013) and the effect of $20 \mathrm{mph}$ traffic speed zones on road injuries (Grundy et al., 
2009). Such studies using ITS have in common that the data consist of a continuous sequence of observations on a population taken repeatedly over time, the intervention marks a defined differentiation between pre- and post-intervention status, the effects of the intervention might not be immediate, and many other factors such as seasonal trends potentially affect the outcome variable before and after the intervention. In the field of veterinary epidemiology, ITS is relatively new. Because BKD is a chronic disease, ITS was considered appropriate for a retrospective cohort study towards estimation of the long-term effect of subclinical BKD. There would be a clear interruption in each production cycle, the infection with BKD, and there are many environmental and management factors that potentially affect the outcome variables to take into account. However, the applicability of the ITS analysis is challenging due to the multilevel structure of the data that is inevitable in aquaculture-related datasets (pens within farms).

There were two objectives to this study. The first objective was to quantify the effect of subclinical BKD on productivity, as measured through mortality, growth and FCR, of Atlantic salmon cultured in marine farms in Atlantic Canada. The second objective was to investigate the applicability of hierarchical ITS analysis for this purpose.

\section{Material and Methods}

We estimated long term effects of BKD by assessing multiple year datasets comprising industry production and health variables from many sites, and employing precise case definitions for clinical and subclinical BKD as previously described in Boerlage et al. (2017). We used a 2-stage interrupted time series analysis (Bhaskaran et al., 2013; Serumaga et al., 2011), in which we first modeled the patterns of BKD between pens within each site, while taking into account the long term effects that are naturally present, i.e. seasonal fluctuations and long term trends. Secondly, we investigated the effect of site-level predictors on the patterns found in the first stage. The interruption was the change from BKD free to (sub)clinical BKD. Our outcomes were the production parameters mortality, growth rate and FCR.

\subsection{Data source}

The study population consisted of Atlantic salmon (Salmo salar L.) cultured in the provinces of New Brunswick (NB), and Newfoundland and Labrador (NL), between 2006 and 2012, that originated from, or were later acquired by, one producer. The industry structure in NB, has not changed substantively since it was described by Hammell and Dohoo (2005a) and McClure et al. (2005), and in NL by O'Brien (2012). The dataset consisted of production data, field observations, test results, and treatments for BKD, and was described in more detail in Boerlage et al. (2017).

\subsection{Terminology}

We used the following terminology. A pen is the smallest grouping of fish within an enclosed net, usually a circular cage. A site is a group of pens in close proximity that are managed together. Sites applied site-level fallow periods where all pens are empty for a period of time. A fish group is a group of fish occupying a pen consistently between stocking and harvesting (there could be more than one fish group within a pen during the study period, separated by a fallow period). The first part of the analysis was performed at the fish-group level.

A site cycle is a collection of fish groups that occupied a site simultaneously for a continuous period. There could be more than 1 site cycle within a site during the study period, separated by a fallow period. The second part of the analysis was done at the site cycle level. For a graphic representation of pen, site, fish groups and site cycles, see Boerlage et al. (2017).

\subsection{Data management}

\subsubsection{The interruption}

Case definitions for BKD in fish groups were developed by (Boerlage et al., 2017) using penlevel and site-level variables. With these definitions, the interruption (i.e. the change from BKD free 
to (sub)clinical BKD), was triggered by either a site-level variable (8 site cycles) or a pen-level variable (17 site cycles). In the latter case, the interruption did not necessarily take place simultaneously for all fish groups within a site cycles. We dealt with this as follows. First, we considered a change of BKD status as a single event (the interruption) if all fish groups experienced the interruption within a 7-week period (8 fish groups). Second, if there were up to 2 exceptions, we adapted their interruption to be the same as the others (1 fish group). Third, if a larger number of fish groups did not experience the interruption within 7 weeks, we dropped observations between interruption of the first fish group and the last fish group ( 9 fish groups).

From the week of interruption, we omitted that week, the previous 6 weeks, and the following 6 weeks (total 13 weeks), with the rationale that 6 weeks was double the time of the 3 weeks it took for mortality to increase after Atlantic salmon were injected with $R$. salmoninarum in an experimental infection trial (Fevolden et al., 1993). Therefore, these omitted weeks represent a buffer for potential inaccuracy of case definition timing, potential delayed physiological response of fish on the interruption and other changes around the interruption that might occur, while avoiding unnecessarily omitting too many records. For an example, see Fig. 1.

\subsubsection{Data restrictions}

Our initial dataset consisted of 104 site-cycles, of which 31 never had BKD, 17 had subclinical BKD only, and 56 had clinical BKD at least once. The total numbers of site cycles by province were $82(26,11,45)$ in NB and $22(5,6,11)$ in NL. To obtain meaningful comparisons and representative estimates, we selected site cycles according to the following selection criteria: 1 ) all fish groups within the site cycles were stocked in the same year, the same season (fall or spring) and within 18 weeks of each other (to assess the predictors stocking season and stocking year); 2) the duration of all site cycles was longer than 16 weeks (to leave sufficient data when omitting 13 weeks around the interruption). These restrictions reduced the dataset to 25 site cycles: 23 from NB and 2 from NL.

Within each fish group, we omitted outcomes in the first 3 weeks post stocking as these might be affected by the process of fish stocking. Next, we selected only site cycles with $>10$ weeks of data before and after the interruption (total $>20$ weeks). Remaining were 18 site cycles (17 from $\mathrm{NB}, 1$ from NL) to be used in the analysis. These site cycles had a mean of 16 (min. 10 - max. 22) fish groups per site cycle.

\subsubsection{Time}

We defined our time series in terms of calendar time and not fish age (see for a discussion Boerlage et al. (2018)), and included fish age as predictor. Fish age was combined with temperature effects into "accumulated degree days since stocking," in which scale two days at five degrees equals the same age as five days at two degrees. To reduce sampling bias at specific sites for temperature measurements, we used a smoothened overall temperature that was obtained by a locally weighted regression method (lowess command) with bandwith 0.01 based on recorded water-temperatures. Using the unsmoothed water temperatures resulted in a less good model fit.

\subsection{Statistical analysis}

The aim of our first stage regression models (fish groups in site cycles) was to investigate whether the long-term variations in the outcomes (mortality, growth, and FCR) were changed at the time of BKD infection, by including an indicator variable for BKD as explanatory variables. The time scale units for the outcomes were weekly (mortality) or monthly (growth and FCR). All time scales were calendar time, and the data was structured in 2 levels; fish groups in site cycles. BKD treatment and its effect in a 12 week window was included as a time-varying covariate (at fish group level), because treatment for BKD may affect the relation between BKD and performance.

\subsubsection{Dependent variables}


Mortality, growth and FCR were the time-varying outcome variables used in this study. Mortality was represented as relative mortality according to equation 1, in which was time in weeks. Relative mortalities of $>80 \%$ were dropped because they occurred around harvest or were considered data recording mistakes. For analysis, mortality as described in equation 1 was transformed by taking the natural logarithm of Mortality(w).

Mortality $_{(w)}=\frac{\left(\text { mortality count }_{(w)}+1\right)}{\text { number of fish per fish group }(w)} \quad$ (equation 1)

Growth was represented as weekly relative growth, averaged per calendar month according to equation 2 , in which $\mathrm{m}$ is time in calendar months. The reason for averaging was that weekly weight in the data set was based on estimations of the management program used, manually adjusted by weight measures taken in the field on a monthly basis, which could cause artificial dips in weight. We therefor considered a monthly average a more suitable level of variation than weekly. Per month, we selected the maximum weight of fish in that month to represent the monthly weight, which in $7 \%$ of the weekly data was not the weight of the last week of the month. The number of weeks per month was variable and therefore taken into account. For example, a month could consist of 2 weeks of data if the other weeks were part of the omitted 13-week data gap representing the interruption. For analysis, growth as described in equation 2 was transformed by taking the square root of $\left(\right.$ Growth $\left._{(\mathrm{m})}+0.4\right)$.

Growth $_{(m)}=\frac{\left(\text { weight }_{(m)}-\text { weig }_{(m-1))} / \text { number of weeks in month m }\right.}{\left.\text { weight }_{(m)}+\text { weight }_{(m-1)}\right) / 2} \quad$ (equation 2)

FCR was represented monthly for the same reason as for growth according to equation 3 . FCR values $<0.5$ were excluded because they were considered data recording mistakes, and were replaced by averages of the FCR in the weeks before and after, where possible; otherwise, they were left as missing. For analysis, fcr as described in equation 3 was transformed by $-\mathrm{FCR}_{(\mathrm{m})}{ }^{\wedge}-0.75$.

$F C R_{(m)}=\frac{\left(\text { feed used }_{m} / \text { number of weeks in mont } m\right.}{\text { biomass }_{(m)}-\text { biomass }_{(m-1)}} \quad$ (equation 3)

All outcome variables were Box-Cox transformed to meet the normality assumptions, and to deem homoscedasticity of model residuals as appropriate.

\subsubsection{First stage model specification}

We used one linear mixed model for each of the 18 site cycles with transformed outcomes, random effects for fish group and additional within-group first order autocorrelation. We controlled for seasonality by including Fourier terms with 2 harmonics per year for long-term effects, and including a linear and quadratic term for fish age and indicators for BKD treatments. We included a lag of one time unit (one week for mortality, one month for growth and FCR) before which BKD was assumed to affect performance. As example, the result for mortality in site cycle 1 can be found in Table E3.

Before arriving to the final model, we explored including fish group as fixed rather than random effect, the use of centered random slopes for accumulated degree days since stocking, different fourier term complexity (1-6 harmonics), use of natural splines (with 4, 7, and 43 knots) instead of a linear and quadratic term for fish age to allow for more flexible curves, including second order autocorrelation, dropping seasonality, and comparing including 2 separate predictors (temperature and time since stocking) rather than accumulated degree days. None of these alternatives were found to have lower AIC than the main model.

\subsection{Second stage; Meta regression}

Meta regression analysis was used to investigate the heterogeneity observed between site cycles, using estimated BKD effects and standard errors from the final models of the first step as dependent variables (Thompson and Higgins, 2002). Several explanatory variables, all at site cycle level, were included. Bay Management Area (BMA), the zoning system in place in NB (Chang et al., 
2007) and NL, was explored as spatial grouping variable. Other variables were the stocking seasons spring (weeks 36 - 13) and other, year of stocking, year of harvesting, duration of previous fallow period, duration of site cycle, average number of lice treatments and number of fish groups per site cycle, see Table 1.

\subsubsection{Meta-analysis models}

Random effect meta-analysis models were used for each of the dependent variables (mortality, growth, FCR), followed by multivariable linear meta-regression in which we investigated all combinations of explanatory variables with significance levels $\leq 0.30$. A significance level of $\leq 0.05$ was used to determine significance in the multivariate model.

\section{Results}

\subsection{Explanatory variables}

The number of maximum accumulated degree days of the fish groups, averaged by site cycle, ranged from 647 to 1028, and the mean duration of site cycles was 110 weeks (Table 1). Only 7 of the site cycles in our study had one or more treatments for BKD and, in 4 of the 7 treated site cycles, not all fish groups were treated. The median number of fish groups per site cycle was 16. Of 10 site cycles, the mean duration of the fallow period was 54 days, for the other 8 site cycles this information was unknown. Sea lice treatments were carried out on average 0.022 times per week. Our site cycles were distributed over 6 BMAs, of which one was in Newfoundland. The 18 site cycles were distributed over 15 sites; 3 times there were 2 site cycles at the same site but at different times. Thirteen of the site cycles stocked their fish groups in the spring.

\subsection{Change in outcomes following BKD infection - crude}

Average difference in weekly mortality post - pre interruption was different for the 18 site cycles, and average differences ranged from $-0.258 \%$ to $1.469 \%$ (Table 2). For weekly growth the difference was negative for most site cycles and ranged from -0.073 to 0.024 grams per bodyweight per fish per week (Table 2). For monthly FCR the difference was between -0.706 and 0.725 (Table 2).

\subsection{Change in outcomes following BKD infection - ITS analysis}

There were time trends in all three outcomes as well as changes in post - pre interruption (example in Figure 1). After allowing for these and other covariates using hierarchical ITS analysis, all three outcomes showed large and significant variation (I-sq from 90 to $96 \%$ ) across site cycles in changes after BKD infection ("BKD effect"), with some increases and some decreases (Figure 2).

Four of the site cycles $(1,6,11$ and 18) had significantly higher mortality after the interruption, which was not explained by seasonal or long-term effects, and seven cycles $(3,4,5,7$, 10, 15 and 16) a significantly lower mortality (Figure 2A). However, overall on average across site cycles mortality was little different after the interruption from before, with coefficient -0.078 (95\% confidence interval: $-0.508,0.352$ indicating that 0 is within the interval and therefore the difference is not significantly different). None of the site-cycle level explanatory variables could explain the variation observed in BKD effect between the site cycles.

There were eight site cycles $(2,4,5,8,9,11,15$, and 17), which had by ITS an improved growth and four $(1,3,6$ and 16) a reduced growth after the interruption. However, the estimated overall mean difference between post and pre interruption in relative growth was $0.00(-0.018$, 0.018) (Figure 2B) on the transformed scale as described in section 2.4.1. Harvesting year explained some of the variation observed between site cycles, but none are strong (Table E4).

Two site cycles (1 and 6$)$ had a reduced FCR and eight site cycles $(3,8,10,11,13,15,16,17)$ a higher FCR after the interruption. The overall estimate of the difference between post and pre interruption was $0.071(-0.007,0.150)$, implying a very slight significantly higher FCR after the 
interruption (Figure 2C). The variation in BKD effect across site cycles could not be explained by any of the meta predictors.

\section{Discussion}

This is to our knowledge the first evidence-based study that explores the long-term effects of subclinical BKD on performance of Atlantic salmon in aquaculture using production data. Despite the recurrent impressions in the industry (personal communication) and in publications (Burnley et al., 2010; Vigneulle and Bruno, 2015) that subclinical BKD reduces performance of Atlantic salmon during the sea rearing phase, we found no evidence of such an effect on mortality or growth, and a very small effect on FCR. We used hierarchical ITS analysis, which enabled us to investigate the effect of BKD infection as an "interruption" in our time series while taking into account long term trends. The potential of ITS for veterinary epidemiology has been noted (Stryhn et al., 2016).

\subsection{Subclinical BKD}

Evidence-based information on the effect of chronic subclinical diseases on performance of fish is scarce. Even though it is accepted that fish can appear healthy and be carriers of several pathogens at the same time (Plumb and Hanson, 2011), there might be internal pathological changes affecting the fish (Mackenzie, 1988), and these could affect performance.

In our study, mortality levels were in the same order of non-outbreak levels described by Hammell and Dohoo (2005b) for aquaculture practices in the same area. At the individual site-cycle level, we observed positive and negative effects of BKD on mortality, but could not explain this with the variables available, such as management area. This is in line with a study towards benchmarking mortality of salmon for a company on the west coast of Scotland, which showed that mortality is highly variable, even though they found that mortality was year dependent (Soares et al., 2011), which we could not verify in this dataset. The absence of a long-term, overall effect of BKD on mortality was unexpected, because we did not omit clinical-BKD episodes, which by definition included elevated mortality due to BKD (Boerlage et al., 2017). We expected additional elevated mortality that might not be noticeable in the field, but that might be apparent when natural variation is accounted for statistically. An explanation for finding no effect could be that the basic level and variation of mortality in Atlantic-salmon aquaculture may be such that even when correcting for structural variation, the potential effect of BKD is not significant. Additionally, the management strategies applied by managers to pens that have been diagnosed with BKD, and of veterinarians dealing with clinical outbreaks, for example reduced handling when infections are suspected by management, could be affecting mortality successfully so that negative effects are diffused.

We observed a similar scenario for growth rates as for mortality. We found an effect of BKD within a few individual site cycles, but not overall. It has been shown that after a stressor, Atlantic salmon can return to, or surpass, their previous growth levels (Stefansson et al., 2009), which might have been the case for these fish after a clinical BKD episode. This analysis on growth rate shows that the hierarchical ITS analysis was successful in correcting for the decreasing growth-rate curve of salmon (see Figure 1B). Without the ITS analysis there would have been a negative effect (as in Figure 1B), because at the end of the site cycle, when growth rate is lowest (Austreng et al., 1987), all site-cycles included in this study are BKD-positive.

We did find a small effect of BKD on FCR. The FCR was overall higher, thus less optimal, when site cycles were infected with subclinical BKD. This higher FCR could be due to BKD, as disease can adversely affect FCR (Shinn et al., 2016). However, the increase in FCR was small and also for FCR here there was a large heterogeneity, so that this relationship was not present for each individual site cycle participating in the study. A general trend of the FCR over time within a production period is unclear and has been reported as constant at changing fish weight (Morkore and Rorvik, 2001) or increasing throughout the production period (Azevedo et al., 2004). If 
variation in this trend is similar for pens within a site cycle, it would have been expected to have little influence on study outcomes because the ITS analysis would have controlled for the trend.

Even though growth rates and FCR are closely related, they represent different mechanisms as generally acknowledged. In this study, we demonstrated the importance of measuring both values, not only because there is a difference in overall effect between them, but also because the effect of some site cycles is different for FCR and growth rate. For example, fish could have an increased FCR but no effect on growth, implying more feed is needed (and thus additional costs for the farm) to achieve the same weight gain.

Perhaps one of the most interesting outcomes of this study was that the variation in effects of BKD on mortality, growth and FCR between the site cycles could not, or only minimally, be explained by the variables that were available to us (Figure 2). As farms optimize their management of disease events, their changing husbandry may also contribute to negating influences and decreasing the ability to detect the influence of factors on BKD occurrence. Another explanation could be the presence of significant interactions between latent or unmeasured variables, which can be complex in open pen aquaculture. For example, zebra fish (Danoi rerio) studied with subclinical infections with microsporidia, showed no direct effect, but adding a stressor led to higher mortality and lower growth in infected zebra fish compared to non-infected zebra fish (Ramsay et al., 2009).

A chronic infection, as is the case for BKD, may result from low pathogenicity of the disease agent, high natural resistance of the host, or acquired immunity by the host (Sindermann, 1990). In aquaculture, management strategies and not the natural cycles dictate the processes of life and death of a host population, therefore in order to understand the dynamics of the pathogen it is useful to look at the pathogen-host interaction in a natural situation. In studies of wild salmon, salmon of all age classes have been found to carry BKD (Banner et al., 1986; Paterson et al., 1981), which may imply that salmon carry their infection until they are able to return to their spawning rivers. In this way they infect future generations by vertical transmission, which is a proven method of transmission for R. salmoninarum (Evelyn et al., 1984; Wiens, 2011). Based on the results, we hypothesize that it may be the natural ecology of the pathogen to cause minimal interference with performance or the probability of successful spawning. Such a low pathogenicity could indicate that vertical transmission is the main strategy to propagate in the low-density host populations (Anderson and May, 1981) such as are the situations in wild salmon populations.

\subsection{Hierarchical ITS analysis}

Time series regression is a method that is developed during the last decade and is making its way into veterinary epidemiology. The hierarchical structure of the data, year classes in site cycles, provided an additional challenge. Previous research has shown that the variation between site cycles in time to first clinical BKD case was large (Boerlage et al., 2018). During the data exploration we found a similar characteristic in this study, and it was not meaningful to capture the long term variation in performance parameters by one single equation across all site cycles (results not shown). There large variation between site cycles may have a wide range of origins, such as variation in sea lice abundance (Boxaspen, 1997), seasons and years in which the site cycles operate (Westcott et al., 2008), management practices such as timing of treatments, nearby boat traffic, seal attacks, and appearance of zooplankton and phytoplankton blooms (Rodger et al., 2011). To deal with the hierarchical structure, we used one equation for a longterm pattern for all fish groups within a site cycle. A similar approach was performed in (Jia et al., 2018), where different ponds with fish were modeled separately. The average numbers of fish groups per site cycle was $10-22$ (Table 1), which provided sufficient observations to model the site cycles separately. Regardless of the complex multilevel structure of the data, we consider the 
hierarchical ITS analysis an appropriate and promising method for data obtained from openwater salmon aquaculture farms.

The salmon aquaculture industry is characterized by rapid adoption of innovation and technology (Asche et al., 2013). Site workers may sit in off-site monitoring rooms in which many day-to-day operations, including monitoring fish behaviour and morbidity and adjusting feeding rates, are initiated and observed through computerized functions. Along with this automation, salmon aquaculture now generates and stores large volumes of data related to health and mortality of their fish stocks. These data exist in the form of time series following fish through production for the entire duration of their site cycles and these records continue to expand and improve in accuracy and validation (Føre et al., 2017). Such time-series data are an excellent source for TSR and related analysis. It is important to continue to explore and optimize the methodology that uses time-series analyses and to design on-farm record systems that are compatible with straightforward extraction of data relevant to studies of factors related to health and productivity.

\section{Conflict of interest}

The authors declare that they have no conflict of interest.

\section{Acknowledgements}

The authors wish to acknowledge the industry partner, Cooke Aquaculture Inc and particularly Dr. Leighanne Hawkins, for their cooperation, and Dr. Nicole O'Brien, veterinary epidemiologist with the Newfoundland and Labrador Department of Fisheries and Land Resources, for her facilitation of diagnostic data collation. This research was undertaken thanks to funding from the Canada Excellence Research Chairs program and Innovation PEI.

\section{References}

Anderson, R.M., May, R.M., 1981. The population dynamics of microparasites and their invertebrate hosts. Philos. Trans. R. Soc. B Biol. Sci. 291, 451-524. https://doi.org/10.1098/rstb.1981.0005

Asche, F., Guttormsen, A.G., Nielsen, R., 2013. Future challenges for the maturing Norwegian salmon aquaculture industry: An analysis of total factor productivity change from 1996 to 2008. Aquaculture 396-399, 43-50. https://doi.org/10.1016/j.aquaculture.2013.02.015

Austreng, E., Storebakken, T., Åsgård, T., 1987. Growth rate estimates for cultured Atlantic salmon and rainbow trout. Aquaculture 60, 157-160. https://doi.org/10.1016/0044-8486(87)90307-3

Azevedo, P. a, Azevedo, P. a, Leeson, S., Leeson, S., Cho, C.Y., Cho, C.Y., Bureau, D.P., Bureau, D.P., 2004. Growth and feed utilization of large size rainbow trout (Oncorhynchus mykiss) and Atlantic salmon (Salmo salar) reared in freshwater: diet and species effects, and responses over time. Aquac. Nutr.

Balfry, S.K., Albright, L.J., Evelyn, T.P.T., 1996. Horizontal transfer of Renibacterium salmoninarum among farmed salmonids via the fecal-oral route. Dis. Aquat. Organ. 25, 63-69. https://doi.org/10.3354/dao025063

Banner, C.R., Long, J.J., Fryer, J.L., Rohovec, J.S., 1986. Occurrence of salmonid fish infected with Renibacterium salmoninarum in the Pacific Ocean. J. Fish Dis. 9, 273-275. https://doi.org/10.1111/j.1365-2761.1986.tb01013.x

Bernal, J.L., Cummins, S., Gasparrini, A., 2017. Interrupted time series regression for the evaluation of public health interventions: A tutorial. Int. J. Epidemiol. 46, 348-355. https://doi.org/10.1093/ije/dyw098

Bhaskaran, K., Gasparrini, A., Hajat, S., Smeeth, L., Armstrong, B., 2013. Time series regression studies in environmental epidemiology. Int. J. Epidemiol. 42, 1187-1195. https://doi.org/10.1093/ije/dyt092 
Boerlage, A.S., Elghafghuf, A., Stryhn, H., Sanchez, J., Hammell, K.L., 2018. Risk factors associated with time to first clinical case of Bacterial Kidney Disease (BKD) in farmed Atlantic Salmon (Salmo salar L.) in New Brunswick, Canada. Prev. Vet. Med. 149, 98-106. https://doi.org/10.1016/j.prevetmed.2017.11.014

Boerlage, A.S., Stryhn, H., Sanchez, J., Hammell, K.L., 2017. Case definition for clinical and subclinical bacterial kidney disease (BKD) in Atlantic Salmon (Salmo salar L.) in New Brunswick, Canada. J. Fish Dis. 40, 395-409. https://doi.org/10.1111/jfd.12521

Boxaspen, K., 1997. Geographical and temporal variation in abundance of salmon lice (Lepeophtheirus salmonis) on salmon (Salmo salar L.). ICES J. Mar. Sci. Sci. 54, 1144-1147.

Burnley, T.A., Stryhn, H., Burnley, H.J., Hammell, K.L., 2010. Randomized clinical field trial of a bacterial kidney disease vaccine in Atlantic salmon, Salmo salar L. J. Fish Dis. 33, 545-557. https://doi.org/10.1111/j.1365-2761.2010.01151.x

Chang, B.D., Page, F.H., Losier, R.J., Lawton, P., Singh, R., Greenberg, D.A., 2007. Evaluation of bay management area scenarios for the southwestern New Brunswick salmon aquaculture industry: aquaculture collaborative research and development program final project report. Can. Tech. Rep. Fish. Aquat. Sci. 2722, v $69 \mathrm{p}$.

Elliott, D.G., Pascho, R.J., Palmisano, A.N., 1995. Brood stock segregation for the control of bacterial kidney disease can affect mortality of progeny chinook salmon (Oncorhynchus tshawytscha) in seawater. Aquaculture 132, 133-144. https://doi.org/10.1016/0044-8486(94)00380-7

Evelyn, T.P.T., Ketcheson, J.E., Prosperi-Porta, L., 1984. Further evidence for the presence of Renibacterium salmoninarum in salmonid eggs and for the failure of povidone-iodine to reduce the intra-ovum infection rate in water-hardened eggs. J. Fish Dis. 7, 173-182. https://doi.org/10.1111/j.1365-2761.1984.tb00921.x

Evenden, A.J., Grayson, T.H., Gilpin, M.L., Munn, C.B., 1993. Renibacterium salmoninarum and bacterial kidney disease - the unfinished jigsaw. Annu. Rev. Fish Dis. 3, 87-104. https://doi.org/10.1016/0959-8030(93)90030-F

Fevolden, S.E., Nordmo, R., Refstie, T., Røed, K.H., 1993. Disease resistance in Atlantic salmon (Salmo salar) selected for high or low responses to stress. Aquaculture 109, 215-224. https://doi.org/10.1016/0044-8486(93)90164-T

Føre, M., Frank, K., Norton, T., Svendsen, E., Alfredsen, J.A., Dempster, T., Eguiraun, H., Watson, W., Stahl, A., Sunde, L.M., Schellewald, C., Skøien, K.R., Alver, M.O., Berckmans, D., 2017. Precision fish farming: A new framework to improve production in aquaculture. Biosyst. Eng. 1-18. https://doi.org/10.1016/j.biosystemseng.2017.10.014

Grundy, C., Steinbach, R., Edwards, P., Green, J., Armstrong, B., Wilkinson, P., 2009. Effect of $20 \mathrm{mph}$ traffic speed zones on road injuries in London, 1986-2006: Controlled interrupted time series analysis. BMJ 339, 31. https://doi.org/10.1136/bmj.b4469

Hammell, K.L., Dohoo, I.R., 2005a. Risk factors associated with mortalities attributed to infectious salmon anaemia virus in New Brunswick, Canada. J. Fish Dis. 28, 651-61. https://doi.org/10.1111/j.1365-2761.2005.00668.x

Hammell, K.L., Dohoo, I.R., 2005b. Mortality patterns in infectious salmon anaemia virus outbreaks in New Brunswick, Canada. J. Fish Dis. 28, 639-50. https://doi.org/10.1111/j.13652761.2005.00667.x

Jia, B., Armstrong, B., Stryhn, H., Gardner, I.A., Chang, H., St-Hilaire, S., 2018. A case study of time-series regression modeling: Risk factors for pond-level mortality of farmed grass carp (Ctenopharyngodon idella) on a southern Chinese farm. Aquaculture 484, 58-64. https://doi.org/10.1016/j.aquaculture.2017.10.037

Lovely, J.E., Cabo, C., Griffiths, S.G., Lynch, W.H., 1994. Detection of Renibacterium salmoninarum infection in asymptomatic Atlantic salmon. J. Aquat. Anim. Health 126-132. 
Mackenzie, K., 1988. Presumptive mycobacteriosis in North-east Atlantic mackerel, Scomber scombrus L. J . Fish Biol 32, 263-275. https://doi.org/10.1111/j.1095-8649.1988.tb05360.x

McClure, C.A., Hammell, K.L., Stryhn, H., Dohoo, I.R., Hawkins, L.J., 2005. Application of surveillance data in evaluation of diagnostic tests for infectious salmon anemia. Dis Aquat Organ 63, 119-127. https://doi.org/10.3354/dao063119

Mesa, M.G., Maule, A.G., Schreck, C.B., 2000. Interaction of Infection with Renibacterium salmoninarum and Physical Stress in Juvenile Chinook Salmon: Physiological Responses, Disease Progression, and Mortality. Trans. Am. Fish. Soc. 129, 158-173. https://doi.org/10.1577/15488659(2000)129<0158:IOIWRS>2.0.CO;2

Morkore, T., Rorvik, K.-A., 2001. Seasonal variations in growth, feed utilisation and product quality of farmed Atlantic salmon (Salmo salar) transferred to seawater as $0+$ smolts or $1+$ smolts. Aquaculture 199, 145-157. https://doi.org/10.1016/S0044-8486(01)00524-5

Murray, A.G., Hall, M., Munro, L.A., Wallace, I.S., 2011. Modelling control options for a disease with hidden sub- clinical infection: bacterial kidney disease in Scottish aquaculture, in: 19th International Congress on Modelling and Simulation, Perth, Australia, 12-16 December 2011. pp. $12-16$.

O'Brien, N., 2012. Evidence-based veterinary medicine in finfish aquaculture in Newfoundland and Labrador. Thesis, 129 pp. https://www.islandscholar.ca/islandora/object/ir\%3A6228.

Pascho, R.J., Elliott, D.G., Streufert, J.M., 1991. Brood stock segregation of spring chinook salmon Oncorhynchus tshawytscha by use of the enzyme-linked immunosorbent assay (ELISA) and the fluorescent antibody technique (FAT) affects the prevalence and levels of Renibacterium salmoninarum infection in progeny. Dis. Aquat. Org., 12: 25-40.

Paterson, W.D., Lall, S.P., Desautels, D., 1981. Studies on bacterial kidney disease in Atlantic salmon (Salmon salar) in Canada. Fish Pathol. 15, 283-292. https://doi.org/10.3147/jsfp.15.283

Plumb, J.A., Hanson, L.A., 2011. Health maintenance and principal microbial diseases of cultured fishes. 3rd ed. John Wiley \& Sons.

Ramsay, J.M., Watral, V., Schreck, C.B., Kent, M.L., 2009. Pseudoloma neurophilia (Microsporidia) infections in zebrafish (Danio rerio): effects of stress on survival, growth and reproduction HHS Public Access. Dis Aquat Organ December 22, 69-84. https://doi.org/10.3354/dao02145

Rodger, H.D., Henry, L., Mitchell, S.O., 2011. Non-infectious gill disorders of marine salmonid fish. Rev. Fish Biol. Fish. 21, 423-440. https://doi.org/10.1007/s11160-010-9182-6

Serumaga, B., Ross-Degnan, D., Avery, A.J., Elliott, R.A., Majumdar, S.R., Zhang, F., Soumerai, S.B., 2011. Effect of pay for performance on the management and outcomes of hypertension in the United Kingdom: interrupted time series study. BMJ 342, d108. https://doi.org/10.1136/bmj.d108

Shinn, A., Pratoomyot, J., Jiravanichapisal, P., Delannoy, C., Kijphakapanith, N., Paladini, G., Griffiths, D., 2016. C ounting the cost of aquatic diseases in Asia. Aquac. Asia Pacific 12, 14-18.

Sindermann, C.J., 1990. Principal diseases of marine fish and shellfish, Academic Press, London.

Soares, S., Green, D.M., Turnbull, J.F., Crumlish, M., Murray, A.G., 2011. A baseline method for benchmarking mortality losses in Atlantic salmon (Salmo salar) production. Aquaculture 314, 712. https://doi.org/10.1016/j.aquaculture.2011.01.029

Stefansson, S.O., Imsland, A.K., Handeland, S.O., 2009. Food-deprivation, compensatory growth and hydro-mineral balance in Atlantic salmon (Salmo salar) post-smolts in sea water. Aquaculture 290, 243-249. https://doi.org/10.1016/j.aquaculture.2009.02.024

Stryhn, H., Jia, B., St-hilaire, S., Armstrong, B., 2016. Time series regression in aquaculture, in: Front. Vet. Sci. Conference Abstract: AquaEpi I - 2016. https://doi.org/10.3389/conf.FVETS.2016.02.00036

Thompson, S.G., Higgins, J.P.T., 2002. How should meta-regression analyses be undertaken and interpreted? Stat. Med. 21, 1559-1573. https://doi.org/10.1002/sim.1187 
Toranzo, A.E., Magariños, B., Romalde, J.L., 2005. A review of the main bacterial fish diseases in mariculture systems. Aquaculture 246, 37-61. https://doi.org/10.1016/j.aquaculture.2005.01.002

Vigneulle, M., Bruno, D.W., 2015. ICES identification leaflets for diseases and parasites of fish and shellfish. Leaflet No. 21 Bacterial kidney disease.

Walley, A.Y., Xuan, Z., Hackman, H.H., Quinn, E., Doe-Simkins, M., Sorensen-Alawad, A., Ruiz, S., Ozonoff, A., 2013. Opioid overdose rates and implementation of overdose education and nasal naloxone distribution in Massachusetts: Interrupted time series analysis. BMJ 346, 1-13. https://doi.org/10.1136/bmj.f174

Westcott, J.D., Stryhn, H., Burka, J.F., Hammell, K.L., 2008. Optimization and field use of a bioassay to monitor sea lice Lepeophtheirus salmonis sensitivity to emamectin benzoate. Dis. Aquat. Organ. 79, 119-131. https://doi.org/10.3354/dao01887

Wiens, G.D., 2011. 9 Bacterial kidney disease (Renibacterium salmoninarum), in: Woo, P.T.K., Bruno, D.W. (Eds.), Fish Diseases and Disorders. CABI, Wallingford, pp. 338-374.

Zion, B., 2012. The use of computer vision technologies in aquaculture - A review. Comput. Electron. Agric. 88, 125-132. https://doi.org/10.1016/i.compag.2012.07.010 
TABLES

Table 1. Summary statistics of site-level explanatory variables used in the model for the second step analysis.

\begin{tabular}{ll}
\hline Continuous variables & Mean (min - max) \\
\hline $\begin{array}{l}\text { Number of fish groups } \\
\text { Duration of fallow period previous } \\
\text { to the site cycle (days) }\end{array}$ & $16(10-22)$ \\
$\begin{array}{l}\text { Duration of the site cycle (weeks) } \\
\text { Average number of sea lice }\end{array}$ & $110(89-125)$ \\
$\begin{array}{l}\text { treatments per fish group per } \\
\text { week in the site cycle }\end{array}$ & $0.022(0-0.131)$ \\
\hline Categorical variables & $\mathrm{N}$ (category- number of observations) \\
\hline BMA & $1-5 ; 2-2 ; 3-2 ; 4-1 ; 5-6 ; 6-1$ \\
Site & 15 \\
Stocking season & Spring-13; other-5 \\
Stocking year & $2006-3 ; 2007-5 ; 2008-5 ; 2009-2 ; 2010-3$ \\
$\quad$ Harvesting year & $2008-3 ; 2009-4 ; 2010-5 ; 2011-3 ; 2012-3$ \\
\hline $\begin{array}{l}\text { a: } 8 \text { missing observations } \\
\text { b: } 1 \text { missing observation }\end{array}$ &
\end{tabular}


Table 2. Summary statistics around interruption: pre and post number of observations and difference between post and pre median mortality, growth and FCR.

\begin{tabular}{|c|c|c|c|c|c|c|c|}
\hline \multirow{4}{*}{$\begin{array}{l}\text { Site } \\
\text { cycle }\end{array}$} & \multicolumn{3}{|c|}{ Weekly } & \multicolumn{4}{|c|}{ Monthly } \\
\hline & \multicolumn{2}{|c|}{ Number of observations } & \multirow{3}{*}{$\begin{array}{l}\text { Difference } \\
\text { in median } \\
\text { Mortality, d }\end{array}$} & \multicolumn{2}{|c|}{ Number of observations } & \multicolumn{2}{|c|}{$\begin{array}{l}\text { Difference } \\
\text { in median }\end{array}$} \\
\hline & Pre & Post & & Pre & Post & Growth $^{b, d}$ & $\mathrm{FCR}^{\mathrm{c}, \mathrm{d}}$ \\
\hline & interruption & interruption & & interruption & interruption & & \\
\hline 1 & 505 & 742 & -0.002 & 135 & 167 & -0.077 & 0.368 \\
\hline 2 & 639 & 831 & -0.023 & 158 & 197 & -0.022 & 0.335 \\
\hline 3 & 300 & 1224 & 0.002 & 85 & 280 & -0.032 & -0.814 \\
\hline 4 & 1467 & 554 & 0.000 & 345 & 134 & 0.009 & -0.855 \\
\hline 5 & 366 & 565 & 0.020 & 90 & 134 & -0.034 & 0.293 \\
\hline 6 & 250 & 867 & -0.003 & 74 & 193 & -0.071 & -0.379 \\
\hline 7 & 821 & 860 & -0.008 & 204 & 204 & -0.042 & 0.419 \\
\hline 8 & 294 & 705 & -0.194 & 83 & 154 & -0.065 & -0.062 \\
\hline 9 & 597 & 1031 & -0.016 & 140 & 244 & -0.027 & 0.144 \\
\hline 10 & 893 & 1008 & 0.029 & 229 & 231 & -0.051 & -0.095 \\
\hline 11 & 1222 & 1136 & 0.011 & 314 & 254 & -0.030 & 0.370 \\
\hline 12 & 1307 & 258 & 0.008 & 308 & 60 & -0.033 & 0.075 \\
\hline 13 & 1059 & 939 & -0.020 & 268 & 212 & -0.034 & 0.400 \\
\hline 14 & 367 & 715 & -0.002 & 94 & 165 & -0.045 & -0.033 \\
\hline 15 & 1147 & 367 & -0.015 & 282 & 73 & -0.023 & 0.226 \\
\hline 16 & 1205 & 785 & -0.001 & 303 & 180 & -0.039 & 0.526 \\
\hline 17 & 1292 & 770 & 0.012 & 313 & 175 & -0.026 & 0.234 \\
\hline 18 & 742 & 701 & -0.006 & 176 & 168 & -0.023 & 0.177 \\
\hline
\end{tabular}

${ }^{a}$ : Weekly percentage of dead fish relative to fish present (Mortality ${ }_{(\mathrm{w})}$ as described in equation 1 multiplied by $\left.100 \%\right)$.

${ }^{\mathrm{b}}$ : Weekly growth, relative to actual weight, and averaged per month (Growth $(\mathrm{m})$ as described in equation 2 ).

c: Monthly FCR ( $\mathrm{FCR}_{(\mathrm{m})}$ as described in equation 3$)$.

: Median value before and after interruption (and Q25, Q75) can be found in the electronic supplement in Table E1 and E2 
FIGURES

Figure 1. For mortality, growth, and FCR an example (site cycle 11) of the time series data. Data were transformed as follows: A) mortality by natural logarithm, B) growth by taking the square root of (growth +0.4 , and C) FCR by (-FCR^-0.75). The figures show weekly (mortality) or monthly (growth and FCR) observations (black circles), estimated seasonal effect (red dots), estimated long term trend (green dots), and the interruption (around June 2011) that represents the change in BKD status.
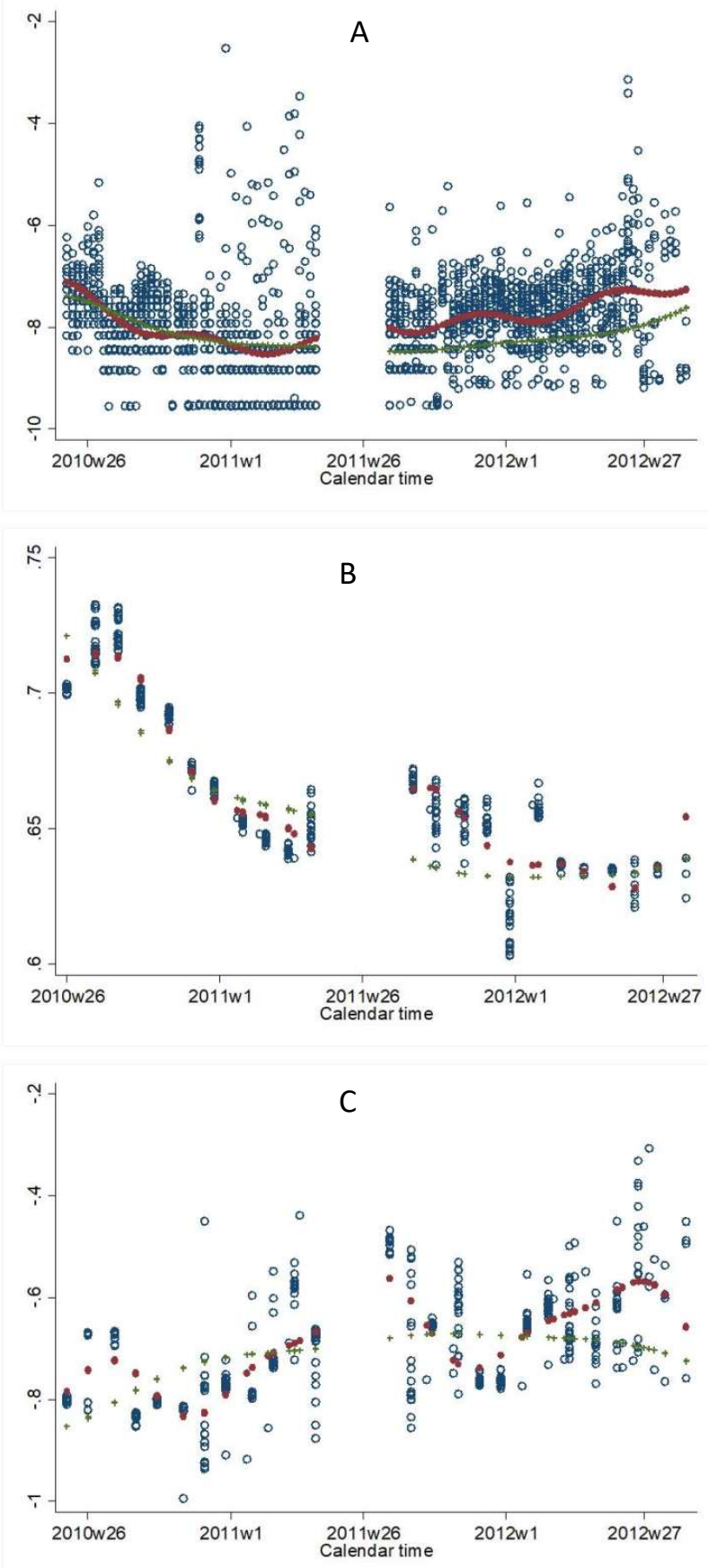
Figure 2. After hierarchical ITS analysis, the effect of the interruption on A) mortality, B) growth, and C) FCR per site. $X$-axis represents values of box-cox transformed variables after the interruption minus before the interruption, representing post-pre BKD difference.

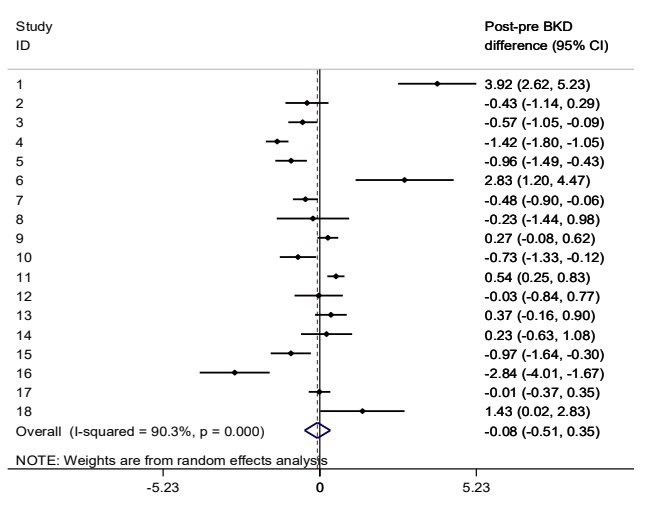

A: Weekly relative mortality

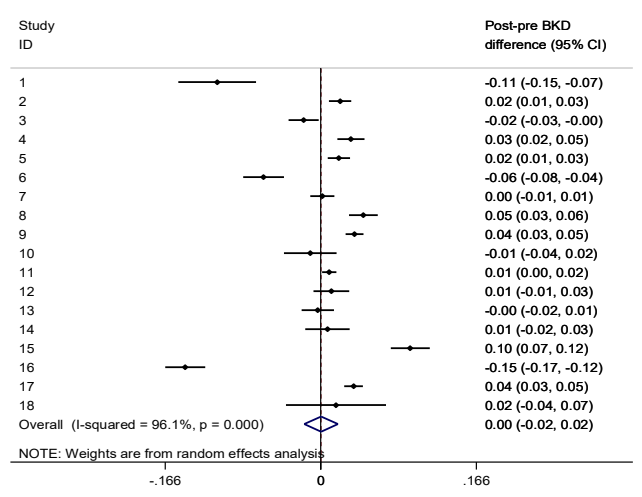

B: Monthly relative growth

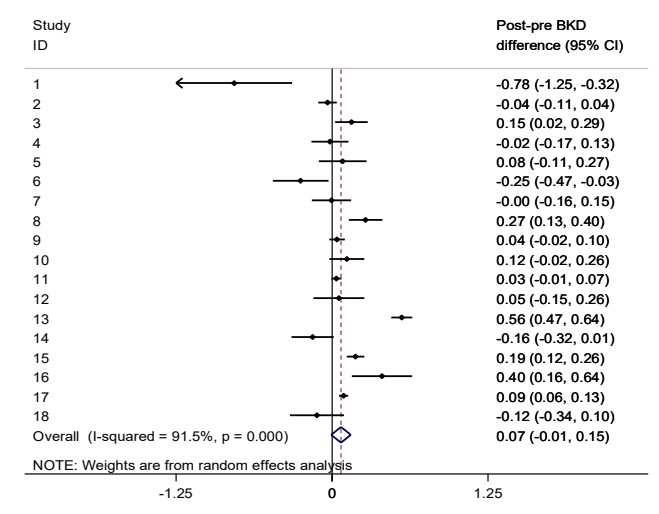

C: Monthly relative food conversion ratio 
ELECTRONIC SUPPLEMENTS

Table E1. Summary statistics of mortality before and after the interruption, median, Q25 and Q75 per site cycle, as used in the model in the first step.

\begin{tabular}{|c|c|c|c|c|c|}
\hline $\begin{array}{r}\text { Site } \\
\text { cycle }\end{array}$ & $\begin{array}{c}\text { After } \\
\text { interruption }\end{array}$ & $N$ & Median & Q25 & Q75 \\
\hline 1 & 0 & 505 & 0.039 & 0.023 & 0.070 \\
\hline 1 & 1 & 742 & 0.037 & 0.020 & 0.076 \\
\hline 2 & 0 & 639 & 0.059 & 0.027 & 0.137 \\
\hline 2 & 1 & 831 & 0.035 & 0.020 & 0.064 \\
\hline 3 & 0 & 300 & 0.060 & 0.034 & 0.172 \\
\hline 3 & 1 & 1,224 & 0.062 & 0.032 & 0.152 \\
\hline 4 & 0 & 1,467 & 0.027 & 0.013 & 0.060 \\
\hline 4 & 1 & 554 & 0.027 & 0.020 & 0.046 \\
\hline 5 & 0 & 366 & 0.038 & 0.021 & 0.090 \\
\hline 5 & 1 & 565 & 0.058 & 0.033 & 0.093 \\
\hline 6 & 0 & 250 & 0.045 & 0.025 & 0.086 \\
\hline 6 & 1 & 867 & 0.042 & 0.015 & 0.100 \\
\hline 7 & 0 & 821 & 0.031 & 0.009 & 0.064 \\
\hline 7 & 1 & 860 & 0.023 & 0.013 & 0.045 \\
\hline 8 & 0 & 294 & 0.321 & 0.130 & 0.960 \\
\hline 8 & 1 & 705 & 0.127 & 0.037 & 0.423 \\
\hline 9 & 0 & 597 & 0.046 & 0.015 & 0.173 \\
\hline 9 & 1 & 1,031 & 0.030 & 0.015 & 0.094 \\
\hline 10 & 0 & 893 & 0.067 & 0.036 & 0.123 \\
\hline 10 & 1 & 1,008 & 0.096 & 0.044 & 0.208 \\
\hline 11 & 0 & 1,222 & 0.029 & 0.014 & 0.063 \\
\hline 11 & 1 & 1,136 & 0.040 & 0.022 & 0.065 \\
\hline 12 & 0 & 1,307 & 0.029 & 0.017 & 0.049 \\
\hline 12 & 1 & 258 & 0.037 & 0.019 & 0.077 \\
\hline 13 & 0 & 1,059 & 0.052 & 0.022 & 0.117 \\
\hline 13 & 1 & 939 & 0.031 & 0.016 & 0.069 \\
\hline 14 & 0 & 367 & 0.048 & 0.019 & 0.159 \\
\hline 14 & 1 & 715 & 0.046 & 0.014 & 0.234 \\
\hline 15 & 0 & 1,147 & 0.033 & 0.020 & 0.074 \\
\hline 15 & 1 & 367 & 0.018 & 0.012 & 0.037 \\
\hline 16 & 0 & 1,205 & 0.032 & 0.019 & 0.053 \\
\hline 16 & 1 & 785 & 0.031 & 0.014 & 0.057 \\
\hline 17 & 0 & 1,292 & 0.035 & 0.016 & 0.081 \\
\hline 17 & 1 & 770 & 0.048 & 0.020 & 0.132 \\
\hline 18 & 0 & 742 & 0.039 & 0.018 & 0.118 \\
\hline 18 & 1 & 701 & 0.033 & 0.021 & 0.059 \\
\hline
\end{tabular}


TableE2. Summary statistics of growth and FCR before and after the interruption, median per site cycle, as used in the model in the first step.

\begin{tabular}{|c|c|c|c|c|c|c|c|c|}
\hline \multirow{2}{*}{$\begin{array}{r}\text { Site } \\
\text { cycle }\end{array}$} & \multirow{2}{*}{$\begin{array}{c}\text { After } \\
\text { interruption }\end{array}$} & \multirow[t]{2}{*}{$N$} & \multirow{2}{*}{$\begin{array}{l}\text { Growth } \\
\text { Median }\end{array}$} & \multicolumn{4}{|c|}{ FCR } & \multirow[b]{2}{*}{ Q75 } \\
\hline & & & & Q25 & Q75 & Median & Q25 & \\
\hline 1 & 0 & 135 & 0.107 & 0.091 & 0.120 & 1.160 & 0.986 & 1.425 \\
\hline 1 & 1 & 167 & 0.030 & 0.013 & 0.047 & 1.528 & 1.293 & 2.038 \\
\hline 2 & 0 & 158 & 0.047 & 0.023 & 0.114 & 1.362 & 1.291 & 1.400 \\
\hline 2 & 1 & 197 & 0.025 & 0.007 & 0.045 & 1.698 & 1.478 & 2.061 \\
\hline 3 & 0 & 85 & 0.064 & 0.054 & 0.105 & 2.211 & 2.154 & 2.642 \\
\hline 3 & 1 & 280 & 0.032 & 0.010 & 0.058 & 1.397 & 1.264 & 1.829 \\
\hline 4 & 0 & 345 & 0.044 & 0.017 & 0.064 & 1.997 & 1.475 & 2.502 \\
\hline 4 & 1 & 134 & 0.053 & 0.027 & 0.124 & 1.143 & 0.914 & 1.681 \\
\hline 5 & 0 & 90 & 0.052 & 0.025 & 0.133 & 1.589 & 1.379 & 1.942 \\
\hline 5 & 1 & 134 & 0.018 & 0.004 & 0.035 & 1.882 & 1.555 & 2.591 \\
\hline 6 & 0 & 74 & 0.092 & 0.081 & 0.098 & 1.645 & 1.444 & 1.757 \\
\hline 6 & 1 & 193 & 0.021 & 0.014 & 0.034 & 1.266 & 1.046 & 1.519 \\
\hline 7 & 0 & 204 & 0.050 & 0.015 & 0.099 & 1.537 & 1.331 & 1.936 \\
\hline 7 & 1 & 204 & 0.008 & 0.002 & 0.032 & 1.956 & 1.207 & 3.065 \\
\hline 8 & 0 & 83 & 0.085 & 0.043 & 0.120 & 1.419 & 1.037 & 1.534 \\
\hline 8 & 1 & 154 & 0.021 & 0.009 & 0.036 & 1.357 & 1.214 & 1.811 \\
\hline 9 & 0 & 140 & 0.044 & 0.025 & 0.095 & 1.197 & 1.004 & 1.401 \\
\hline 9 & 1 & 244 & 0.017 & 0.009 & 0.032 & 1.341 & 1.264 & 1.487 \\
\hline 10 & 0 & 229 & 0.078 & 0.038 & 0.121 & 1.805 & 1.469 & 2.230 \\
\hline 10 & 1 & 231 & 0.028 & 0.017 & 0.047 & 1.710 & 1.350 & 2.101 \\
\hline 11 & 0 & 314 & 0.051 & 0.025 & 0.091 & 1.397 & 1.317 & 1.677 \\
\hline 11 & 1 & 254 & 0.021 & 0.004 & 0.032 & 1.766 & 1.498 & 2.028 \\
\hline 12 & 0 & 308 & 0.040 & 0.018 & 0.063 & 1.529 & 1.251 & 2.630 \\
\hline 12 & 1 & 60 & 0.007 & 0.005 & 0.008 & 1.604 & 1.490 & 1.67 \\
\hline 13 & 0 & 268 & 0.059 & 0.052 & 0.068 & 1.030 & 0.898 & 1.491 \\
\hline 13 & 1 & 212 & 0.026 & 0.019 & 0.035 & 1.430 & 1.285 & 1.888 \\
\hline 14 & 0 & 94 & 0.056 & 0.022 & 0.084 & 1.276 & 0.997 & 1.918 \\
\hline 14 & 1 & 165 & 0.011 & 0.005 & 0.026 & 1.243 & 1.116 & 1.335 \\
\hline 15 & 0 & 282 & 0.039 & 0.029 & 0.074 & 1.117 & 0.995 & 1.214 \\
\hline 15 & 1 & 73 & 0.017 & 0.007 & 0.062 & 1.343 & 1.130 & 1.417 \\
\hline 16 & 0 & 303 & 0.054 & 0.007 & 0.122 & 1.399 & 0.974 & 2.302 \\
\hline 16 & 1 & 180 & 0.015 & 0.008 & 0.027 & 1.926 & 1.547 & 2.458 \\
\hline 17 & 0 & 313 & 0.037 & 0.023 & 0.055 & 1.406 & 1.340 & 1.617 \\
\hline 17 & 1 & 175 & 0.011 & 0.007 & 0.021 & 1.640 & 1.480 & 1.885 \\
\hline 18 & 0 & 176 & 0.047 & 0.022 & 0.111 & 1.162 & 1.009 & 1.500 \\
\hline 18 & 1 & 168 & 0.024 & 0.010 & 0.039 & 1.339 & 1.243 & 1.408 \\
\hline
\end{tabular}


Table E3: Example of first stage model output for mortality in site cycle 1.

\begin{tabular}{|c|c|c|c|c|c|}
\hline Term $^{*}$ & Coefficient & SE & $\mathrm{p}$ & \multicolumn{2}{|c|}{$95 \% \mathrm{Cl}$} \\
\hline Linear term for fish age & -0.022 & 0.003 & $<0.01$ & -0.027 & -0.017 \\
\hline Quadratic term for fish age & 0.000 & 0.000 & $<0.01$ & 0.000 & 0.000 \\
\hline BKD treatment & -0.242 & 0.143 & 0.091 & -0.522 & 0.038 \\
\hline BKD positive & 3.924 & 0.667 & $<0.01$ & 2.616 & 5.232 \\
\hline Random effect parameters & & Variance & SE & \multicolumn{2}{|c|}{$95 \% \mathrm{Cl}$} \\
\hline Fish group & & 0.032 & 0.022 & 0.008 & 0.121 \\
\hline \multirow{2}{*}{$\begin{array}{l}\text { Within-group first order } \\
\text { autocorrelation }\end{array}$} & rho & 0.264 & 0.034 & 0.197 & 0.329 \\
\hline & $\operatorname{var}(e)$ & 0.921 & 0.046 & 0.835 & 1.017 \\
\hline
\end{tabular}

*From this output are missing: the constant and Fourier terms for long term effects.

Table E4. Results of random-effects meta regression of harvesting year on coefficients representing the effect of BKD status on growth.

\begin{tabular}{llll}
\hline Variable & $\beta$ & se & P-value \\
\hline $\begin{array}{llll}\text { Harvesting year } \\
2008\end{array}$ & Ref. & & 0.04 \\
2009 & -0.088 & 0.033 & 0.02 \\
2010 & 0.017 & 0.032 & 0.61 \\
2011 & -0.023 & 0.035 & 0.52 \\
2012 & 0.004 & 0.035 & 0.91 \\
\hline$I^{2}=95 \%$ & & &
\end{tabular}

